\title{
A Humanização da Assistência ao Parto na Percepção de Estudantes de Medicina
}

\author{
The Humanization of Childbirth Care from \\ the Perspective of Medical Students
}

Maria Tereza Maia Penido Rebello João Felício Rodrigues Neto ${ }^{I}$

PALAVRAS-CHAVE:

- Parto Humanizado;

- Educação Médica;

- Obstetrícia;

- Pesquisa Qualitativa.

KEYWORDS:

- Humanizing Delivery;

- Medical Education;

- Obstetrics;

- Qualitative Research.

Recebido em: 05/09/2011

Aprovado em: 02/04/2012

REVISTA BRASILEIRA DE EDUCAÇÃO MÉDICA

\section{RESUMO}

A humanização vem-se destacando na assistência ao trabalho de parto e nascimento com ênfase na legitimidade científica e defesa dos direitos das mulheres. Entretanto, o processo de humanização da assistência à saúde deve ser amplamente inserido na formação dos profissionais de saúde, sob pena de não se concretizar caso não ocorram adesão e participação efetiva dos novos profissionais. Foi realizado um estudo de abordagem qualitativa, exploratório-descritivo, com o objetivo de verificar a concepção de parto humanizado na perspectiva de estudantes de Medicina. Os dados, obtidos em entrevistas individuais, foram submetidos à análise de conteúdo e agrupados por categorias temáticas, sendo identificadas 18 unidades de contexto que geraram 41 unidades de registros, das quais emergiram duas categorias e cinco subcategorias: (1) humanização associada à inclusão da parturiente (acolhimento e acompanhante) e (2) humanização relacionada à assistência adequada (tecnologia do cuidado, parto como evento fisiológico, equipe multiprofissional). Este estudo mostrou a associação, pelos estudantes de Medicina, de aspectos humanísticos aos aspectos biomédicos da assistência ao parto, confirmando o processo de mudança que vivenciamos na educação médica.

\section{ABSTRACT}

The humanization has been increasing in the assistance for labor and delivery with emphasis on scientific legitimacy and rights of women. However, the process of humanization in health care should be broadly placed in the formation of health professionals under the penalty of not being materialized if an adhesion and effective participation by the young professionals do not happen. We conducted a qualitative study, exploratory and descriptive, with the objective of verifying the conception of humanized childbirth from the perspective of medical students. The data obtained through personal interviews were submitted to content analysis and grouped by themes, where we could identify 18 context units that generated 41 units of records from which emerged two categories and five subcategories: (1) humanization related to the inclusion of the mother (reception and companion) and (2) humanization related to the appropriate assistance (technology of care, childbirth as physiological event, multidisciplinary team). This study showed the association, by the medical students, of humanistic aspects and biomedical aspects of childbirth care, confirming the process of change that we are experiencing in medical education. 


\section{INTRODUÇÃO}

De modo bem amplo, a relação entre Humanismo e Medicina pode ser compreendida por, pelo menos, duas vertentes: por um lado, podemos enfatizar a inter-relação entre as ciências humanas ou humanidades, como a Sociologia, Psicologia, Antropologia, Filosofia e a Medicina; por outro, podemos entender que este tema se refere à relação da medicina científica com o ser humano mediante uma abordagem que considere também o seu lado emocional, social e cultural, ou seja, de uma forma mais humanizada. Essas duas visões não são excludentes ${ }^{1}$.

A humanização é um movimento com presença crescente e disseminada em nosso país. Inicialmente, surge como a busca de um ideal, em diferentes frentes de atividades e com vários significados, sendo que cada uma destas frentes determina um conjunto de questões práticas, teóricas, comportamentais e afetivas que teriam uma resultante humanizadora ${ }^{2}$.

Embora a expressão "humanização" da assistência compreenda um amplo conjunto de noções e iniciativas, ainda necessita de definição mais clara, identificando-se mais como uma diretriz de trabalho, um movimento de parcela dos profissionais e gestores, do que um aporte teórico prático. Afinal, o que significa humanizar a assistência à saúde? Pressupõe-se que a prática em saúde era (des)humanizada? Esses questionamentos ainda são feitos, evidenciando o estranhamento que o termo ocasiona.

Segundo Deslandes ${ }^{3}$, o termo "humanização" se refere à assistência que valoriza a qualidade do cuidado do ponto de vista técnico associadamente ao reconhecimento dos direitos do paciente, de sua subjetividade e referências culturais, significando ainda a valorização do profissional e do diálogo intra e interequipes.

Para $\operatorname{Rios}^{4}$, a humanização na área da saúde pode ser compreendida como: princípio de conduta de base humanística e ética; movimento contra a violência institucional na área da saúde; política pública para a atenção e gestão no Sistema Único de Saúde (SUS); metodologia auxiliar para a gestão participativa e tecnologia do cuidado na assistência à saúde. Por tecnologia do cuidado, entende-se a ênfase dada ao princípio da integralidade e do desenvolvimento de tecnologias leves destinadas ao aprimoramento da atenção ${ }^{4}$.

Já Benevides e Passos ${ }^{5}$, orientados pela análise foucaultiana do poder, ressaltam que não há como garantir uma política nacional de humanização da saúde sem que se confronte com o tema do humanismo contemporâneo - uma tarefa difícil, pois o pensamento no século XX foi marcado por uma crítica anti-humanista que deve agora ser retomada para que possamos nos reposicionar. Para esses autores, a humanização seria uma estratégia de interferência no processo de produção de saúde, considerando que sujeitos, quando mobilizados, são capazes de transformar realidades, transformando-se a si próprios nesse mesmo processo. Ainda segundo esses autores, o tema humanização no campo da saúde está, então, intrinsecamente ligado ao processo de constituição do SUS no Brasil, sendo também resultado das reivindicações que impunham não só a recolocação das funções e deveres do Estado, como também os direitos dos homens ${ }^{5}$.

Para Ferreira", muitos sentidos podem ser dados à "humanização", mas, de forma geral, ela aparece como a necessária redefinição das relações humanas na assistência e mesmo da compreensão da condição humana e dos direitos humanos, segundo o entendimento de que os usuários têm o direito de conhecer seus diagnósticos e tratamentos e de decidir sobre eles.

Atualmente, nos serviços de saúde, esse movimento se traduz em alguns aspectos práticos, como, por exemplo: melhorar a relação médico-paciente, organizar atividades de convívio, garantir acompanhante na internação da criança, implementar novos procedimentos na atenção psiquiátrica e na atenção ao parto, amenizar as condições do atendimento aos pacientes internados no centro de terapia intensiva, denunciar a "mercantilização" da medicina e tantas outras proposições². Na medida em que o termo "humanizar" e todo o seu léxico correspondente se tornam recorrentes na fala dos diferentes atores envolvidos na assistência à saúde, há uma interpretação e aplicabilidade desses termos que dependem das motivações, das relações com as atividades e das dinâmicas das relações sociais estabelecidas ${ }^{6}$

$\mathrm{Na}$ assistência ao trabalho de parto e nascimento, o movimento de humanização vem-se destacando no cenário internacional e nacional de várias maneiras, com ênfase na legitimidade científica e defesa dos direitos das mulheres ${ }^{7-10}$. O nascimento é um dos eventos mais importantes na vida da mulher e por isto pode afetar o resto da sua vida, tanto física como emocionalmente. Em décadas passadas, o parto foi intensamente medicalizado em muitos países, gestação e nascimento foram entendidos como processos patológicos que necessitavam de monitorização intensiva, e as intervenções médicas no parto aumentaram, especialmente na América do Norte?

A humanização do parto se destaca como uma abordagem que vem sendo implementada com o objetivo de tornar o nascimento uma experiência positiva e satisfatória para a mulher e sua família. Segundo Wagner, humanização do parto significa colocar a mulher no centro e no controle das decisões sobre o que irá acontecer e pode ser entendida como redução do excesso de intervenção e medicamentos no parto, empoderamento da mulher e prática obstétrica baseada em evidência. 
Ainda segundo esse autor, existiriam cerca de três tipos de assistência obstétrica no mundo: (1) a altamente medicalizada, que utiliza avanços tecnológicos e centrada no médico, com marginalização das enfermeiras obstetras, como ocorre nos Estados Unidos da América, Irlanda, Rússia, República Checa, França, Bélgica, Brasil urbanizado; (2) abordagem humanizada com forte autonomia das enfermeiras obstetras e baixas taxas de intervenção, como na Holanda, Nova Zelândia e países escandinavos; (3) uma mistura das duas abordagens, como ocorre na Inglaterra, Canadá, Alemanha, Japão e Austrália ${ }^{10}$.

No Brasil, o movimento pela humanização da assistência ao parto apresenta vários sentidos, segundo Diniz, sendo que cada um deles explicita uma reivindicação de legitimidade de discurso, embora possa haver ainda uma superposição entre eles 7,8 . Com base em um estudo de duas maternidades "humanizadas" do SUS, essa autora discute os diferentes (e às vezes contraditórios) sentidos do termo na assistência ao parto no Brasil: humanização como assistência baseada em evidência; humanização como reivindicação e defesa dos direitos humanos; humanização referida ao resultado da tecnologia adequada na saúde da população; humanização como legitimidade profissional e corporativa de um redimensionamento dos papéis e poderes na cena do parto; humanização referida à legitimidade financeira dos modelos de assistência, da racionalidade no uso dos recursos; humanização referida à legitimidade da participação da parturiente nas decisões sobre sua saúde; humanização como direito ao alívio da dor ${ }^{8}$.

Por outro lado, vários autores comentam que o processo de humanização da assistência à saúde não é restrito aos espaços assistenciais, pelo contrário, deve ser amplamente inserido na formação dos profissionais de saúde, sob pena de não se concretizar caso não ocorram adesão e participação efetiva dos novos profissionais ${ }^{4,11-14}$. Sendo assim, as instituições de ensino também debatem a formação humanística no ensino superior em saú$\mathrm{de}^{15-19}$. No Brasil, a discussão sobre a formação médica ocasionou a elaboração, discussão e publicação das Diretrizes Curriculares para os Cursos de Graduação em Medicina, homologadas em outubro de 2001, quando o Ministério da Educação e Cultura estabeleceu como modelo de médico desejável para o País:

[...] O médico com formação generalista, humanista, crítica e reflexiva. Capacitado para atuar, pautado em princípios éticos, no processo de saúde-doença em seus diversos níveis de atenção, com ações de promoção, prevenção, recuperação e reabilitação à saúde, na perspectiva da integralidade da assistência, com senso de responsabilidade social e compromisso com a cidadania, como promotor da saúde integral do ser humano ${ }^{20}$.(p.1)
Obviamente, muitas mudanças estão e estarão ocorrendo ao considerarmos a organização e estrutura física das instituições de saúde, a formação médica e as relações de trabalho e sua lógica de produção. Sendo assim, existe um novo horizonte de possibilidades, tanto para melhorar a qualidade da assistência quanto para uma ética relacional, pautada na busca da satisfação equilibrada entre usuário, profissional e gestor. Mas a fundamentação teórico-prática neste campo necessita ainda de exploração e investimento ${ }^{3}$.

Considerando a magnitude do tema, optamos por analisar a humanização sob a perspectiva da formação médica, por meio da assistência humanizada ao parto. Acreditamos que, ao investigar os conceitos apreendidos sobre a humanização da assistência ao parto pelos estudantes, seremos capazes de analisar as concepções de estudantes de Medicina sobre humanização e práticas obstétricas humanizadoras.

Este estudo justifica-se pelo fato de que acreditamos ser o processo de humanização necessário na assistência à saúde, e a visão dos estudantes de Medicina sobre esse processo é fundamental para que possamos entender como vem ocorrendo o processo ensino-aprendizagem sobre um tema amplo, polissêmico e até mesmo novo na formação médica.

\section{PERCURSO METODOLÓGICO}

\section{Cenário do Estudo}

Esta pesquisa foi realizada na Universidade Estadual de Montes Claros (Unimontes), localizada na cidade de mesmo nome, no norte de Minas Gerais.

\section{Delineamento}

Foi realizado um estudo de abordagem qualitativa, exploratório-descritivo, acerca da concepção dos estudantes de Medicina sobre a humanização da assistência ao parto. Como as ações humanizadoras envolvem processos dinâmicos e complexos, sua avaliação deve conter uma abordagem ampliada, que inclua os "comos" e os "porquês" do processo. A abordagem qualitativa se mostra bastante adequada por incluir estudos de significados, significações, ressignificações, representações psíquicas, representações sociais, simbolizações, simbolismos, percepções, pontos de vista, perspectivas, vivências, experiências de vida, analogias ${ }^{21}$.

Para a obtenção dos dados, a técnica de pesquisa utilizada foi a de entrevista individual, com a seguinte pergunta norteadora: "Para você, o que é humanização da assistência ao parto?".

Os sujeitos envolvidos haviam concluído o internato em Ginecologia e Obstetrícia até oito semanas antes da data das entrevistas, durante o décimo período do curso de Medicina. 
As entrevistas foram realizadas em outubro e novembro de 2010, em salas individuais das instituições onde os estudantes cursavam o internato, em horário definido de acordo com a disponibilidade deles. Com duração de até 40 minutos, as entrevistas foram gravadas em formato digital. Elas foram realizadas após obtenção do Termo de Consentimento Livre e Esclarecido, elaborado segundo a Resolução no 196/96, do Conselho Nacional de Saúde e aprovado pelo Comitê de Ética em Pesquisa (processo no 1.929 , aprovado em 16/04/2010). As respostas gravadas em áudio foram depois transcritas integralmente, respeitando-se as pausas e outras expressões que puderam auxiliar a tradução da realidade. Definiu-se o número de estudantes entrevistados após a realização de análises parciais e a percepção de que já eram "suficientes para realizar aquilo a que nos propusemos"22.

As transcrições foram feitas em até cinco dias para melhor aproveitamento da memória, possibilitando obter dados sem desvio de interpretação. Antes da aplicação, as entrevistas foram pré-testadas com dois residentes do serviço.

Os dados qualitativos, obtidos nas entrevistas, foram submetidos à análise de conteúdo, definida por Bardin como um conjunto de técnicas de análise das comunicações que utiliza procedimentos sistemáticos e objetivos de descrição do conteúdo das mensagens para obter indicadores que permitam a inferência de conhecimentos relativos às condições de produção/recepção destas mensagens ${ }^{23}$. Optamos pela análise por categorias temáticas, considerada por Minayo como apropriada para as investigações qualitativas em saúde ${ }^{24}$. Segundo Bardin, o tema é a unidade de significação que se liberta naturalmente de um texto analisado, segundo critérios relativos à teoria que serve de guia à leitura ${ }^{25}$.

Inicialmente, fez-se uma pré-análise do material transcrito, por meio de repetidas leituras (leituras flutuantes), retomando simultaneamente os questionamentos e os objetivos iniciais da pesquisa, criando-se indicadores que orientassem a interpretação final. A partir deste ponto, unidades de contextos foram sendo separadas do texto, e destas unidades foram sendo retiradas as unidades de registro, sendo que, na maioria das situações, uma única unidade de contexto apresentou mais de uma unidade de registro ${ }^{26}$. As unidades de registro foram classificadas e agrupadas de acordo com seus significados a partir de categorias criadas a posteriori ou de forma empírica.

\section{RESULTADOS E DISCUSSÃO}

$\mathrm{Na}$ análise temática, foram identificadas 18 unidades de contexto, que geraram 41 unidades de registro, das quais emergiram duas categorias e cinco subcategorias:

\section{Humanização associada à inclusão da paciente}

1.1 Acolhimento

1.2 Presença de acompanhante

\section{Humanização relacionada à assistência adequada}

Tecnologia do cuidado

Parto como evento fisiológico

Equipe multiprofissional

Por inclusão da paciente, entendemos todas as ações de assistência à saúde que culminam com a inclusão da perspectiva do paciente. Essa perspectiva é representada por sua experiência de "adoecer", expectativas a respeito de como "o problema" será abordado, repercussões na rotina de vida e no contexto social, participação nas propostas terapêuticas. Os modelos de atenção médica que valorizam as dimensões físicas, psíquicas e sociais, tais como o modelo biopsicossocial e o método clínico centrado no paciente, são exemplos de assistência que enfatizam a importância da inclusão da perspectiva do paciente ${ }^{27}$.

Todos os entrevistados associaram humanização da assistência ao parto com o termo acolhimento. Evidencia-se que esse termo significa para esses estudantes a ênfase no diálogo, com direito à informação e participação ativa da parturiente; a melhora na relação médico-paciente; a assistência integral e a chamada assistência "não violenta" com respeito aos direitos humanos e aos direitos reprodutivos. As falas seguintes caracterizam bem esses significados:

\footnotetext{
"Eu acho que a humanização do parto envolve você acolher aquela gestante, explicar todo o processo que vai acontecer com ela, as fases[...]" (E5)

“Eu acho que o principal é que não estão só tendo as informações, eles estão vendo o que está acontecendo. Para mim, humanizar é isso, no sentido dela acompanhar todo o processo e não simplesmente executar, ela ser executada na verdade." (E1)

"Quando você passa a entender a paciente de uma maneira mais humana, você passa a atentar para as necessidades dela[...]" (E3)

"Humanização da assistência ao parto seria você ter uma boa relação médico-paciente, no caso, com a parturiente[...]" (E2)
}

Esses conceitos estão de acordo com alguns dos sentidos que Diniz ${ }^{8}$ aponta para a humanização da assistência ao parto. Segundo essa autora, a humanização da assistência ao parto pode ser associada à legitimidade da participação da parturien- 
te nas decisões sobre sua saúde e à melhora na relação médico-paciente ou enfermeira-paciente, com ênfase na importância do diálogo. A mesma autora menciona ainda a humanização como legitimidade política da reivindicação e defesa dos direitos das mulheres na assistência ao nascimento, um cuidado que promova o parto seguro, mas, também, uma assistência não violenta, relacionada às ideias de "humanismo" e de "direitos humanos"

Rios $^{4}$, ao discutir o surgimento da humanização e aprofundar seus conceitos, também menciona a humanização como um movimento contra a violência institucional na área da saúde, ressaltando que essa violência decorre de relações sociais marcadas pela sujeição dos indivíduos. Deslandes ${ }^{3}$ também afirma que resgatar a humanidade do atendimento é ir contra a violência, sendo que esta representa a antítese do diálogo, a negação do "outro". Essa autora sublinha ainda que a violência diz respeito aos maus-tratos físicos e psicológicos, uma completa e radical negação dos direitos dos usuários, e lembra, ainda, que manifestações de violência também podem ter o usuário como agressor, expressando o desespero de não obter atendimento médico ${ }^{3}$.

Mabuchi e Fustinoni ${ }^{13}$ caracterizam humanizar o parto como dar às mulheres o que lhes é de direito: um atendimento seguro, acolhedor e que respeite suas necessidades físicas, emocionais, psicológicas, sociais e espirituais, independentemente do profissional que dela cuide ou da instituição onde ela se encontre. Mas, ao estudarem o significado dado pelo profissional de saúde para parto humanizado, em uma pesquisa qualitativa com perspectiva fenomenológica realizada em hospital público da cidade de São Paulo, concluem que esse conceito ainda é um desafio em termos de realidade.

Avaliando especificamente a humanização da assistência ao parto no contexto da formação em Obstetrícia de uma Faculdade de Medicina em São Paulo, Hotimsky e Schraiber ${ }^{15}$ avaliaram o entendimento dos estudantes sobre o tema, após análise de material produzido a partir do acompanhamento de uma disciplina de Obstetrícia e Ginecologia em dois contextos: na sala de aula e em visita de um grupo de alunos a um serviço "humanizado" de atenção ao parto. Alguns estudantes identificaram humanização como um termo que se refere às relações entre os sujeitos envolvidos na assistência ao parto e a um conjunto de rotinas assistenciais; outros, como respeito e cuidado que a equipe profissional e o hospital têm com as gestantes; e outros, ainda, como parto normal com a presença de acompanhante. As autoras concluem que o pluralismo de correntes e suas propostas de intervenção dificultam, na perspectiva de ensino, a formação do pensamento crítico e o domínio das tomadas de decisão, fazendo com que os estudantes acreditem que a aplicação de protocolos fixos é mais benéfica e segura para pacientes e médicos ${ }^{15}$.
Sobre a presença de acompanhante, todos os entrevistados associaram a noção de humanização da assistência ao parto a esse direito, caracterizando este acompanhante como um familiar ou a doula (acompanhante de parto), conforme exemplificado abaixo:

\author{
"No momento do trabalho de parto, saber a questão do acom- \\ panhante, perguntar se ela deseja ter um acompanhante na \\ sala de parto." (E2) \\ "Aí vem toda esta questão que é aceitar o acompanhante no \\ pré-parto, aceitar o acompanhante durante todo o trabalho \\ de parto." (E3) \\ "Eu acho que faz parte disso também ter um acompanhante \\ dentro da sala." (E4)
}

"Faz parte também o direito a acompanhante." (E6)

O guia de atenção ao parto normal da Organização Mundial da Saúde (OMS), que segue critérios bastante estritos de Medicina Baseada em Evidências, classifica o respeito à escolha da mulher quanto ao acompanhante durante o trabalho de parto e parto como categoria A, o que significa práticas comprovadamente úteis e que devem ser estimuladas ${ }^{28}$. Segundo Rattner $^{7}$, a presença de um acompanhante da escolha da mulher é a melhor "tecnologia" disponível para um parto bem-sucedido, segundo estudos baseados em evidências. Daí deriva a Lei 11.108/2005, denominada Lei do Acompanhante, que garante às parturientes o direito à presença de acompanhante durante o trabalho de parto, parto e pós-parto imediato, no âmbito do Sistema Único de Saúde ${ }^{29}$. Entretanto, o fato de todos os entrevistados apontarem esse aspecto como fundamental ou, até mesmo, conceitual para a assistência humanizada pode refletir uma visão limitada do processo de humanização, em que continua prevalecendo a obediência a uma "nova" rotina hospitalar rígida, imposta por norma governamental e não a utilização de uma tecnologia inovadora, cientificamente comprovada como benéfica.

Diniz ${ }^{8}$ também considera a inclusão do pai no parto e a presença de doulas como um dos sentidos da humanização, estando esse aspecto associado à legitimidade da participação da parturiente nas decisões sobre sua saúde. Diferentemente de uma noção relativa a direitos sociais, aqui prevalece a tradição liberal, de direitos do consumidor à escolha, ampliando a legitimidade do modelo da Medicina Baseada em Evidências ${ }^{8}$. Esse aspecto de direito à escolha é bem ilustrado na seguinte fala:

"Deixar ela à vontade, respeitar as vontades, os desejos da gestante... a respeito do trabalho de parto, no momento do 
trabalho de parto, saber a questão do acompanhante, perguntar se ela deseja ter um acompanhante na sala de parto, se ela quer deambular no trabalho de parto, como ela se sente mais confortável, como ela vai querer ter o parto, a posição que ela deseja, mais confortável, menos dolorosa." (E2)

O direito à escolha nos remete ao empoderamento da mulher, aspecto mencionado em vários artigos internacionais, associado à definição de humanização, ${ }^{9,0,30,31}$. Behruzi et al. ${ }^{9}$ consideram parto humanizado como aquele que promove a participação ativa da mulher na tomada de decisão sobre a assistência no seu trabalho de parto e parto, com a vantagem do conhecimento especializado de médicos e não médicos e que permite a todos trabalharem juntos como iguais, envolvendo o uso de tecnologia e intervenção médica baseados em evidência. A fala anterior demonstra a visão de que a humanização pode tornar o parto uma experiência positiva e satisfatória para a mulher e sua família.

A assistência humanizada ao parto se relaciona com a assistência adequada e segura para o binômio materno-fetal, na perspectiva dos estudantes entrevistados, conforme as seguintes expressões:

"Preocupação em acertar, não errar, não prejudicar o paciente, praticamente isso." (E7)

"Acho que no momento do parto você tem o auge da coisa porque é o momento de maior urgência do ponto de vista clínico, pode ter altas complicações [...] daí vem a necessidade de você começar a estabelecer o processo de humanização desde o início para nesse momento do parto, do pós-parto [...], atendê-la da melhor forma." (E3)

"E eu acho que o principal é amparar, dar conforto, tentar dar o máximo de segurança para aquela paciente naquele momento." (E6)

Apesar dos relatos de uso de tecnologia adequada ocasionando maior segurança, nota-se que os estudantes têm esta noção de forma pouco aprofundada. É bem descrito na literatura que as normatizações do Programa de Humanização do Pré-Natal e Nascimento do Ministério da Saúde ${ }^{32}$ se baseiam em recomendações sobre tecnologias adequadas para nascimento e parto normal da Organização Mundial da Saúde ${ }^{33}$, sendo que essas recomendações foram estabelecidas com base em estudos consistentes, segundo critérios bastante estritos de Medicina Baseada em Evidências ${ }^{8,28}$. Nem todos os estudantes associaram a humanização da assistência ao parto ao método mais seguro para mãe e recém-nascido ou mesmo a associaram à Medicina Baseada em Evidências, sendo que os estudos sobre eficácia e segurança na assistência à gravidez, parto e pós-parto, realizados numa grande colaboração internacional por meio de metodologia de revisão sistemática, foram os primeiros passos do que viria a ser o movimento pela Medicina Baseada em Evidências ${ }^{8}$. Esse aspecto, provavelmente, reflete o cenário nacional, em que, embora essas recomendações seguras tenham sido instituídas, pouco se sabe sobre seu uso e impacto na prática cotidiana brasileira e, até mesmo, internacional, como afirmam Rocha e Novaes ${ }^{28}$.

Ao realizar uma análise documental, orientada pela perspectiva de análise de conteúdo, dos dois principais textos oficiais produzidos pelo Ministério da Saúde - o Programa Nacional de Humanização da Assistência Hospitalar (PNHAH) ${ }^{34}$ e o Manual $\mathrm{PNHAH}^{35}$-, Deslandes ${ }^{3}$ também identifica a humanização "como a capacidade de oferecer atendimento de qualidade, articulando os avanços tecnológicos com o bom relacionamento". Sabe-se que possuir alta tecnologia e não dispor da delicadeza do cuidado desumaniza a assistência, porém não ter recursos tecnológicos, quando necessário, gera estresse e conflito entre profissionais e usuários, sendo igualmente um fator desumanizador do cuidado. Mas a autora ressalta que, embora ambos os itens constituam a qualidade do sistema, o "fator humano" é considerado mais estratégico pelo documento do $\mathrm{PNHAH}^{3}$.

A humanização estaria também associada ao resultado da tecnologia adequada em termos de saúde da população, ou seja, além dos melhores resultados individuais, o resultado é visto em sua dimensão coletiva, em termos epidemiológicos ou de saúde pública. A adequação tecnológica resultaria em melhores resultados com menos agravos iatrogênicos maternos e perinatais ${ }^{8}$. Esse é o foco da Iniciativa Maternidade Segura, em que a racionalidade no uso de recursos apropriados aparece como um conceito diferente do acesso quantitativo a consultas pré-natais, a leitos e procedimentos, independentemente de seu conteúdo e adequação ${ }^{36}$. Esse sentido se torna ainda mais claro à medida que as evidências científicas demonstram que o excesso de intervenção leva a um aumento da morbimortalidade materna e neonatal, postulando uma redução das intervenções iatrogênicas como forma de promoção da saúde. Segundo as recomendações da OMS, "no parto normal, deve haver uma razão válida para interferir sobre o processo natural"33. Esse conceito de menor intervenção é apontado por um dos estudantes:

“[...] também essa política de menor intervenção, de não intervenção, de naturalização do parto, de maneira a tornar mais uma vivência humana do que um procedimento médico." (E3)

A mudança dos protocolos de intervenção chega a ser interpretada como modelo precário de atenção ao parto, na 
visão dos alunos estudados por Hotimsky e Schraiber ${ }^{15}$. Essas autoras perceberam que a noção de parto natural assume uma conotação negativa, ligada à ideia de precariedade e retrocesso para os alunos avaliados, uma oposição à assistência moderna, que incorpora vários avanços tecnológicos. A tecnologia fascina todos os envolvidos, principalmente os estudantes de Medicina, e comumente muitos veem a proposta de não intervenção no momento do parto como ausência de assistência, evidenciando que nem sempre estaria em jogo a disputa pelo protagonismo na cena do parto, ou seja, os aspectos puramente relacionais ${ }^{15}$. Segundo Rios ${ }^{4}$, a tecnologia que é capaz de estender a sobrevida humana e diminuir o sofrimento causado por males que acometem a saúde se tornou um intermediário que afasta os profissionais do contato mais próximo com o paciente, não só porque agiliza o atendimento e aumenta a produtividade numérica, mas, também, porque fascina e captura o interesse dos profissionais de saúde, particularmente dos médicos. Essa autora conclui que as transformações tecnológicas da medicina e o modo como se organiza hoje o trabalho médico não favorecem o discurso e a prática da humanização ${ }^{4}$.

A formação médica tecnocrática ainda está em nosso meio, apesar de tantas mudanças. Provavelmente, muitos dos atuais docentes tiveram sua formação baseada no modelo biomédico, e, obviamente, os estudantes ainda recebem essas influências. Na prática, a presença da temática "humanização" nas escolas formadoras de profissionais de saúde é tímida. Se, por um lado, muitos hospitais-escola têm Comitês de Humanização, por outro, o tema ainda é relativamente recente no cotidiano da maioria das práticas de atenção e ensino. Nota-se, também, que ainda é prevalente nos hospitais a ideia da humanização voltada para ações pontuais, que amenizam as tensões cotidianas da vida intra-hospitalar".

Além das evidências científicas, para a adoção da postura da não intervenção no momento do parto, a humanização da assistência ao parto engloba também o reconhecimento do parto como evento fisiológico. Esse aspecto é reconhecido na seguinte fala:

"De naturalização do parto, de maneira a tornar mais uma vivência humana do que um procedimento médico." (E3)

Alguns autores tentam conceituar de forma diferente o parto normal e o parto baseado na assistência tecnocrática, considerando como parto normal aquele que ocorre conforme a fisiologia, sem intervenções desnecessárias ${ }^{10,36}$. Segundo Wagner ${ }^{10}$, o parto vaginal, cuja assistência inclui o conjunto de intervenções de rotina, típico do respectivo contexto geográfico e cultural, deveria se chamar "parto típico".
Para alguns estudantes, outro aspecto associado à noção de humanização foi a assistência multiprofissional. Isto pode sugerir uma valorização do papel de vários profissionais da saúde e não apenas do médico, além de representar uma melhoria nas condições de trabalho em geral, um incremento nos recursos humanos envolvidos na assistência ao parto. As falas seguintes ilustram o aspecto de assistência multiprofissional associada ao conceito de humanização:

\section{"Assistência de qualidade mesmo à gestante, tanto por parte do obstetra, como do acadêmico que esta lá, como do técnico que está lá, de todas as pessoas que estão envolvidas naquele processo." (E4) \\ "Uma equipe de enfermagem preparada para aquela situa- ção." (E6) \\ "Os funcionários, auxiliares de enfermagem, equipe médica envolvida, todas as pessoas envolvidas, elas têm uma cultu- ra." (E1)}

Ao pensarmos em assistência multiprofissional, estamos abordando o trabalho em equipe, e, nesse enfoque, existiriam vários aspectos. Um deles, já mencionado e enfatizado nas falas citadas, seria a melhoria na qualidade da assistência para o usuário, ao ser atendido por especialidades que se complementam e que trabalham em sinergia para alcançar o objetivo maior: a saúde do usuário. Outra faceta do trabalho em equipe, não mencionada pelos estudantes, estaria ligada ao aspecto relacional entre os profissionais de saúde que comporiam a equipe e a reorganização dos processos de trabalho. Nesse sentido, a humanização não teria como foco apenas o usuário, mas incluiria o profissional de saúde, envolvendo-se também com a saúde do próprio trabalhador.

Ayres $^{38}$, ao discorrer sobre humanização numa perspectiva filosófica, menciona que seria "um ideal de construção de uma livre e inclusiva manifestação dos diversos sujeitos no contexto da organização das práticas de atenção à saúde, promovida por interações sempre mais simétricas, que permitam uma compreensão mútua entre seus participantes e a construção consensual dos seus valores e verdades" ${ }^{\prime 38}$. O próprio documento ministerial trata da ideia de humanização como melhoria das condições de trabalho do cuidador, afirmando que "é necessário cuidar dos próprios profissionais da área da saúde, constituindo equipes de trabalho saudáveis"34.

A partir do momento em que existe uma equipe, existe a possibilidade de trabalhar junto, em cooperação, em prol do bem comum: a saúde do usuário e do trabalhador, a satisfação do usuário e do trabalhador. Assim, a humanização alcança 
também os processos de gestão e organização do trabalho nos serviços de saúde. Uma gestão "acolhedora", com "ênfase no diálogo", "que respeite os direitos humanos", que inclua o pensar e o fazer coletivos.

Infelizmente, essa outra faceta da equipe multiprofissional não é evidenciada pelos estudantes, demonstrando que, na graduação, é necessário enfocar igualmente os quatro aspectos mencionados nas Diretrizes Curriculares: "o médico com formação generalista, humanista, crítica e reflexiva"20. Segundo Rego e Koifman ${ }^{19}$, é preciso proporcionar, durante a formação médica, oportunidades regulares e de qualidade para que os alunos desenvolvam consciência crítica, autonomia e consciência social. Nos termos de Paulo Freire, o compromisso com um ensino formativo e crítico-reflexivo tem que se traduzir numa educação libertadora e democrática.

\section{CONSIDERAÇÕES FINAIS}

A discussão acerca da humanização da assistência ao parto, na perspectiva de estudantes de Medicina, engloba dois temas amplos, extremamente relevantes e atuais: o processo de humanização da assistência ao parto e a educação médica. Este estudo mostrou que os estudantes de Medicina associam a humanização da assistência ao parto a acolhimento, direito ao acompanhante, segurança, menor intervenção e equipe multiprofissional. A maior ênfase foi dada ao acolhimento, que envolve fornecimento de informações, atenção às necessidades individuais e melhora da relação médico-paciente. Nota-se, ainda, o reconhecimento do parto como um evento fisiológico que necessita de menor intervenção e a importância do envolvimento de profissionais não médicos.

Diante desses achados, podemos vislumbrar, no tocante à educação médica, a associação de aspectos humanísticos aos aspectos biomédicos da assistência, caracterizando o processo de mudança que vivenciamos na educação médica e que culminou com as Novas Diretrizes Curriculares. Obviamente, essa mudança é gradual e de longo prazo, necessitando sobretudo da sensibilização dos docentes para sua implantação.

O processo de humanização da assistência ao parto é amplo, e analisá-lo sob a perspectiva de estudantes de Medicina é um caminho, mas existem muitos outros envolvidos, principalmente se considerarmos uma instituição de ensino. A avaliação das concepções sobre esse processo por parte das pacientes, dos professores e dos outros profissionais envolvidos seria extremamente válida para uma melhor compreensão do ensino, aprendizagem e prática da assistência humanizada ao parto.

O momento é de desafio: contemplar a prática da assistência médica atual nos moldes da humanização, oferecendo tec- nologia adequada, associada à ética relacional e, ainda, preparar os futuros profissionais de saúde para essa nova prática em um momento de reestruturação curricular e de reflexão sobre a vida de estudante e de médico. Sem dúvida alguma, essa reflexão envolve a recuperação do desejo e do prazer de cuidar do próximo não apenas como uma forma de trabalho ou de se superar tecnicamente, mas também como um modo de ajudar o outro e concretizar uma troca de experiências, enriquecendo os dois lados, o do médico e o do paciente.

\section{REFERÊNCIAS}

1. Giglio AD. Medicina e Humanismo. Rev Assoc Med Bras. 2007;53(3):189-207

2. Puccini PT, Cecílio LCO. A humanização dos serviços e o direito à saúde. Cad Saúde Pública. 2004;20(5):1342-53.

3. Deslandes SF. Análise do discurso oficial sobre a humanização da assistência hospital. Ciênc. saúde coletiva. 2004;9(1):7-14.

4. Rios IC. Humanização: a essência da ação técnica e ética nas práticas de saúde. Rev bras educ med. 2009;33(2):253-61.

5. Benevides R, Passos E. A humanização como dimensão pública das políticas de saúde. Ciênc saúde coletiva. 2005;10(3):561-71.

6. Ferreira J. O Programa de Humanização da Saúde: dilemas entre o relacional e o técnico. Saude soc. 2005;14(3):111-8.

7. Rattner D. Humanização na atenção a nascimentos e partos: breve referencial teórico. Interface. 2009;13(1 Suppl): 595-602.

8. Diniz CSG. Humanização da assistência ao parto no Brasil: os muitos sentidos de um movimento.Ciênc saúde coletiva. $2005 ; 10(3): 627-37$.

9. Behruzi R, Hatem M, Fraser W, Goulet L, Li M, Misago C. Facilitators and barries in the humanization of childbirth practice in Japan. BMC Pregnancy and Childbirth. 2010;10:25.

10. Wagner M. Fish can't see water: the need to humanize birth. Intern J Gynecol Obstet. 2001;75:S25-37.

11. Goulart BNG, Chiari BM. Humanização das práticas do profissional de saúde - contribuições para reflexão. Ciênc saúde coletiva.2010;15(1):255-68.

12. Griboski RA, Guilhem D. Mulheres e Profissionais de saúde: o imaginário cultural na humanização ao parto e nascimento. Texto Contexto Enferm. 2006;15(1):107-14.

13. Mabuchi AS, Fustinoni SM. O Significado dado pelo profissional de saúde para trabalho de parto e parto humanizado. Acta Paul. Enferm. 2008; 21(3): 420-26.

14. Nagahama EEI, Santiago SM. Práticas de atenção ao parto e os desafios para humanização do cuidado em dois hospitais 
vinculados ao Sistema Único de Saúde em município da região sul do Brasil. Cad Saúde Pública 2008; 24 (8): 1859-68.

15. Hotimsky SN, Schraiber LB. Humanização no contexto da formação em obstetrícia. Ciênc Saúde Coletiva. 2005;10(3): 639-49.

16. Rego S, Gomes AP, Siqueira-Batista R. Bioética e Humanização como temas transversais na formação médica. Rev Bras Educ Med. 2008;32(4):482-91.

17. Rios IC, Lopes Júnior A, Kaufman A, Vieira JE, Scanavino MT, Oliveira RA. A Integração das disciplinas de humanidades médicas na Faculdade de Medicina da USP - Um Caminho para o Ensino. Rev bras educ med. 2008; 32 (1): 112-21.

18. Wachtler C, Lundin S, Troein M. Humanities for medical students? A qualitative study of a medical humanities curriculum in a medical school program. BMC Medical Education. 2006;6(16).

19. Rego S, Koifman L. Educação Médica e justiça: um desafio para o século 21. Rev bras educ med. 2007;31(3):201-2.

20. Brasil. Ministério da Educação. Conselho Nacional de Educação. Diretrizes Curriculares Nacionais do curso de graduação em Medicina. [online]. [capturado 12 jan 2011]. Disponível em: http://www.abem-educmed.org.br/cne_ minuta_resolucao.htm

21. Nogueira-Martins MCF, Bógus CM. Considerações sobre metodologia qualitativa como recurso para o estudo das ações de humanização em saúde. Saude soc. 2004;13(3):44-57.

22. Bogdan R, Biklen S. Investigação Qualitativa em Educação - Uma introdução à teoria e aos métodos. Coleção Ciências da Educação. Portugal: Porto Editora, 1997.

23. Bardin L. Análise de Conteúdo. 4a ed. Lisboa: Edições 70, 2009.

24. Minayo MCS. O desafio do conhecimento: pesquisa qualitativa em saúde. 11a ed. São Paulo: HUCITEC, 2008.

25. Caregnato RCA, Mutti R. Pesquisa qualitativa: Análise de discurso versus análise de conteúdo. Texto Contexto Enferm. 2006;15(4):679-84.

26. Franco MLPB. Análise de Conteúdo. Brasília: Liber Livro Editora, 2005.

27. Ballester D, Zucolotto SMC, Gannam SSA, Escobar AMU. A inclusão da perspectiva do paciente na consulta médica: um desafio na formação do médico. Rev. bras. educ. med. 2010; 34(4): 598-606.

28. Rocha JA, Novaes PB. Uma reflexão após 23 anos das recomendações da Organização Mundial da Saúde para parto normal. Femina. 2010;38(3): 119-26.

29. Brasil. Lei 11.108, de 7 de abril de 2005. Altera a Lei 8.080, de 19 de setembro de 1990, para garantir às parturientes o direito à presença de acompanhante durante o trabalho de parto, parto e pós-parto imediato, no âmbito do Sistema Único de Saúde - SUS. Diário Oficial da União, Brasília, 8 abr.2005. Seção1, p.1.

30. Page L. The humanization of birth. Intern J Gynecol Obstet. 2001;75:S55-58

31. Page L. Human resources for maternity care: the present system in Brazil, Japan, North America, Western Europe and New Zealand. Intern J Gynecol Obstet. 2001;75:S81-88.

32. Brasil. Ministério da Saúde. Programa de Humanização no pré-natal e nascimento. Brasília: Secretaria de Políticas de Saúde; 2000.

33. World Health Organization. Care in Normal Birth: A Practical Guide. Maternal and Newborn Health/Safe Motherhood Unit. Geneva: WHO, 1996.

34. Brasil. Ministério da Saúde. Programa Nacional de Humanização da Assistência Hospitalar. Brasília: Ministério da Saúde; 2000.

35. Brasil. Ministério da Saúde. Manual do PNHAH. Brasília: Ministério da Saúde; 2000.

36. Tita ATN, Stringer JSA, Goldenberg RL, Rouse DJ. Two Decades of the Safe Motherhood Initiative. Obst Gynecol. 2007;110(5):972-6.

37. Diniz CSG. Entre a técnica e os direitos humanos: possibilidades e limites da humanização da assistência ao parto. São Paulo; 2001. Doutorado [Tese] - Universidade de São Paulo.

38. Ayres JRCM. Hermenêutica e humanização das práticas de saúde. Ciência \& Saúde Coletiva. 2005;10(3):549-60.

\section{CONTRIBUIÇÃO DOS AUTORES}

Maria Tereza M. P. Rebello participou da definição do tema, revisão bibliográfica, delineamento metodológico, coleta, análise e interpretação dos dados, discussão dos resultados, redação do artigo e revisão final. João Felício Rodrigues Neto participou da definição do tema, delineamento metodológico, coleta, análise e interpretação dos dados, discussão dos resultados, redação do artigo e revisão final.

\section{CONFLITO DE INTERESSSES}

Declarou não haver.

\section{ENDEREÇO PARA CORRESPONDÊNCIA}

Maria Tereza Maia Penido Rebello

Hospital Universitário Clemente Farias - Unimontes

Av. Cula Mangabeira, 562

Santo Expedito - Montes Claros

CEP. 39401-001 - MG

E-mail: mariatepenido@hotmail.com 